\title{
A Burden of Physical Inactivity in School-Age Students: The Early Beginning of Cardiometabolic Risk
}

\author{
Pedro Paulo da Silva Soares, ${ }^{1,2}$ Gabriel Dias Rodrigues ${ }^{1,2} \bullet$ \\ Laboratory of Experimental and Applied Exercise Physiology, Department of Physiology and Pharmacology, Fluminense Federal University, ${ }^{1}$ Niterói, RJ - Brazil. \\ National Institute for Science \& Technology - INCT Physical (In)activity \& Exercise, CNPq, ${ }^{2}$ Niterói, RJ - Brazil. \\ Editorial referring to the article: Physical Activity Level, Anthropometric and Cardiovascular Profile Among Students in Sergipe State \\ Attending Public Schools
}

It is well-known that sedentarism has a close association with the risk of cardiovascular and metabolic diseases. The physical inactivity lifestyle contributes to the prevalence of obesity and hypertension in children, highlighting a big health problem since most individuals who were hypertensive and obese in childhood/ adolescence become hypertensive and obese adults ${ }^{1}$. On the other hand, physical exercise is a frontline non-pharmacological strategy to control and treat hypertension, as well as to prevent obesity, which should be encouraged among children/adolescents to reduce cardiometabolic risk in adulthood ${ }^{2}$. In this context, the mapping of risk factors associated with hypertension at the early age should be considered a primary step to plan public policies for disease prevention and health promotion, reducing the burden on healthcare resources ${ }^{3}$. Both obesity and high blood pressure have multifactorial causes, among them low levels of physical activity in adults, children, and adolescents. It is of utmost relevance to investigate the prevalence of physical activity levels in scholars, mainly in a country such as Brazil, with enormous disparities among regions.
In the current issue of the International Journal of Cardiovascular Sciences, Azevêdo et al. ${ }^{4}$ investigated physical activity levels, as well as the anthropometric and cardiovascular profile in school-age students attending public schools in the state of Sergipe, northeast of Brazil. The study reported high rates of physical inactivity for both boys and girls, and increased blood pressure in overweight school-age students. Regarding anthropometric profiles, intriguing data showed a high prevalence of low body weight in the age group from 16 to 17 years for both sexes. In contrast, a previous study found a high prevalence of overweight/obesity in school-age students in a city of the Brazilian South region ${ }^{5}$, suggesting a discrepancy between the Brazilian South and Northeast regions that must be considered for Brazilian public policies in health promoting at the primary care level ${ }^{3}$. From a practical perspective, physical education classes, as well as the public schools' pedagogic programs, must work together for health promoting and health education ${ }^{6}$, and physical activity should be encouraged to prevent cardiovascular risk starting from childhood to adult life.

\section{Keywords}

Sedentarism; Students; Exercise; Adolecents; Physical Activity; Risk Factors; Metabolic Diseases; Public Health. 


\section{References}

1. Chen X, Wang Y. Tracking of blood pressure from childhood to adulthood: A systematic review and meta-regression analysis. Circulation. 2008; 117(25):3171-80.

2. Cornelissen VA, Smart NA. Exercise training for blood pressure: a systematic review and meta-analysis. J Am Heart Assoc. 2013; 2(1): e004473.

3. Bielemann RM, da Silva BGC, Coll C de VN, Xavier MO, da Silva SG. Burden of physical inactivity and hospitalization costs due to chronic diseases. Rev Saude Publica. 2015; 49:75.

4. Azevêdo LM, Santos LS, Pardono E, Almeida JA, Menezes AS. Physical Activity Level, Anthropometric and Cardiovascular Profile Among
Students in Sergipe State Attending Public Schools. Int J Cardiovasc Sci.2021;34(3):255-261.

5. Reuter CP, Burgos LT, Camargo MD, Possuelo LG, Reckziegel MB, Reuter EM et al. Prevalence of obesity and cardiovascular risk among children and adolescents in the municipality of Santa Cruz do Sul, Rio Grande do Sul. Sao Paulo Med J. 2013; 131(5):323-30.

6. Rodrigues GD, Alves Junior ED. Perfil de qualidade de vida e atividade física habitual de adultos participantes das aulas de educação física da Educação de Jovens e Adultos. Rev Bras Prescrição Fisiol Exerc. 2016;10:62. 